\title{
New specimen of the rare requiem shark Eogaleus bolcensis from the Bolca Lagerstätte, Italy
}

Gabriele Larocca Conte, Enrico Trevisani, Paolo Guaschi, and Federico Fanti

Acta Palaeontologica Polonica 65 (3), 2020: 547-560 doi:https://doi.org/10.4202/app.00725.2020

A rare carcharhinid specimen (slab and counter-slab, MSNPV 24625-24626) from the world-renowned Eocene Bolca locality was recently rediscovered during a restoration project started in 1989 by the Museo di Storia Naturale di Pavia. The individual, the largest Eogaleus bolcensis known from Bolca, is disarticulated and lies in a massive limestone matrix, suggesting its provenience from the Monte Postale site. While assessing its taxonomic status, multiple morphological affinities and ontogenetic trends within the Bolca Carcharhiniformes assemblage where documented. Eogaleus bolcensis is here distinguished from the school shark Galeorhinus cuvieri exclusively according to dermal denticle morphology, suggesting partial overlap of ecologic and trophic niches between the two species. Further, measurements and meristic counts taken on different traits of E. bolcensis (two individuals) and G. cuvieri (five individuals) specimens show high degree of similarities. The ratios "trunk length/total length" and "sum of vertebral centra (head region)/total length" of four complete individuals of the fossil assemblage were averaged and employed to estimates the total length of MSNPV 24625-24626. Here, the total length of MSNPV 24625-24626 is estimated in about $172.1 \pm 0.1 \mathrm{~cm}$. The same approach is applied to MCSNV T.311 (E. bolcensis, holotype) and MNHN F.Bol.516 (G. cuvieri, holotype), two partially-preserved fossil individuals from Bolca locality. To support the ontogenetic variability among the Bolca shark assemblage, the age of the fossil individuals was estimated following the Von Bertalanffy Growth Function, using the modern chondrichthyans growth parameters as a reference. Data presented here suggest that all G. cuvieri specimens are juvenile individuals, whereas the E. bolcensis specimens were young-adult.

Key words: Chondrichthyes, Carcharhinidae, Triakidae, Eogaleus, Galeorhinus, Von Bertallanfy Growth Function, age classes, Eocene, Europe.

Gabriele Larocca Conte [glaroccaconte@ucmerced.edu], Environmental System, University of California Merced, 5200 North Lake Rd., 95343, Merced, California, United States of America; and Museo Geologico Giovanni Capellini, Alma Mater Studiorum, Università di Bologna, Via Zamboni 63, 40126, Bologna, Italy. Enrico Trevisani [trevisani.enrico@comune.fe.it ], Museo di Storia Naturale di Ferrara, Via De Pisis 24, 44121, Ferrara, Italy. Paolo Guaschi [paolo.guaschi@unipv.it], Museo di Storia Naturale 
dell’Università di Pavia, Piazza Botta 9-10, 27100, Pavia, Italy. Federico Fanti [federico.fanti@unibo.it], Dipartimento di Scienze Biologiche, Geologiche e Ambientali, Alma Mater Studiorum, Università di Bologna, Via Zamboni 67, 40126, Bologna, Italy; and Museo Geologico Giovanni Capellini, Alma Mater Studiorum, Università di Bologna, Via Zamboni 63, 40126, Bologna, Italy.

This is an open-access article distributed under the terms of the Creative Commons Attribution License (for details please see creativecommons.org), which permits unrestricted use, distribution, and reproduction in any medium, provided the original author and source are credited.

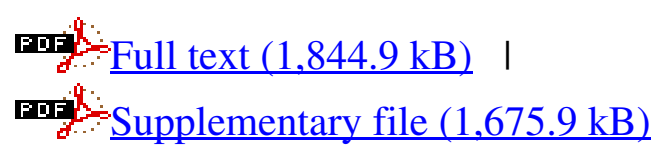

